\title{
Ongoing Archaeological Research on Fais Island, Micronesia
}

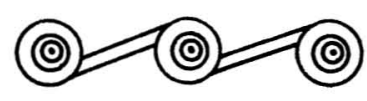

MICHIKO INTOH

With ACCUMUlated ARChAeOlogical DATA from Oceania, particularly in the southwestern part, the complex cultural history of Micronesia has been recognized. Several human dispersal routes to Micronesia are suggested based on linguistic and archaeological evidence (Intoh 1997). Two or more dispersals to western Micronesia and several dispersals from the south have been proposed. The Caroline Islands, situated in the middle of Micronesia, is thus a key place to explore dispersal routes into Micronesia. This paper describes ongoing archaeological research on Fais Island in the Caroline Islands, Federated States of Micronesia (FSM).

Previously, two excavation projects were conducted on Fais Island, the first in 1991 (a midden), and the second in 1994 (a prehistoric cemetery). The 1991 research on Fais Island yielded a number of significant results, such as evidence for early settlement, a long history of keeping domesticated animals, and continuous contacts with high islands. The 1994 research concentrated on the burial ground dated between the thirteenth century A.D. and the early historic period. A total of 13 burials were unearthed and examined (Lee 2006).

The third phase of the research was conducted in 2005, with several research goals:

1. to explore the prehistoric expansion of habitation areas through time;

2. to obtain more controlled evidence for the introduction of domesticated animals; and

3. to examine prehistoric resource management on a small coral island.

Since various investigations of excavated materials are still in progress, this paper describes some results obtained mainly from the Powa site (FSPO) on the southern coastal plain. Deep cultural deposits, over three meters, were excavated which contained a number of artifacts made of shell, coral, and bone as well as imported potsherds. Considerable amounts of natural remains were also unearthed such as fish, mammals (dog, pig, rat, and porpoise), birds, marine turtles, shellfish, and crustaceans. A new series of $\mathrm{C}^{14}$ dates were obtained which may require modifying the previously reported chronology of Fais prehistory. 


\section{FAIS ISLAND ARCHAEOLOGY}

Physical Background

Fais is a raised coral island situated at $9^{\circ} 46^{\prime} \mathrm{N}$ and $140^{\circ} 3^{\prime} \mathrm{E}$ (Fig. 1). The nearest island is Ulithi atoll, lying about $80 \mathrm{~km}$ west. Farther west from Ulithi, about $180 \mathrm{~km}$, Yap Island complex is located. This is the nearest high island around Fais. Politically, Fais belongs to the Yap State of the Federated States of Micronesia.

Fais Island is elongated in shape in the direction of northeast to southwest (Fig. 2). It is about $2.7 \mathrm{~km}$ in length and about $1.1 \mathrm{~km}$ in width. The total land area is only $2.8 \mathrm{~km}^{2}$. A narrow fringing reef surrounds the island except for the northeast end and the west, where rough waves pound steep cliffs. There is neither a safe anchorage nor a good landing place at the island. It is difficult to go through narrow channels when the weather is rough. Inside the fringing reef, a narrow sandy beach extends along the coast. The bottom of the sea between the fringing reef and the beach is covered with fused, old coral and has little sandy patches. Unlike an atoll environment, neither coral nor bivalve shells live in the lagoon and not many reef fishes are seen inside the reef.

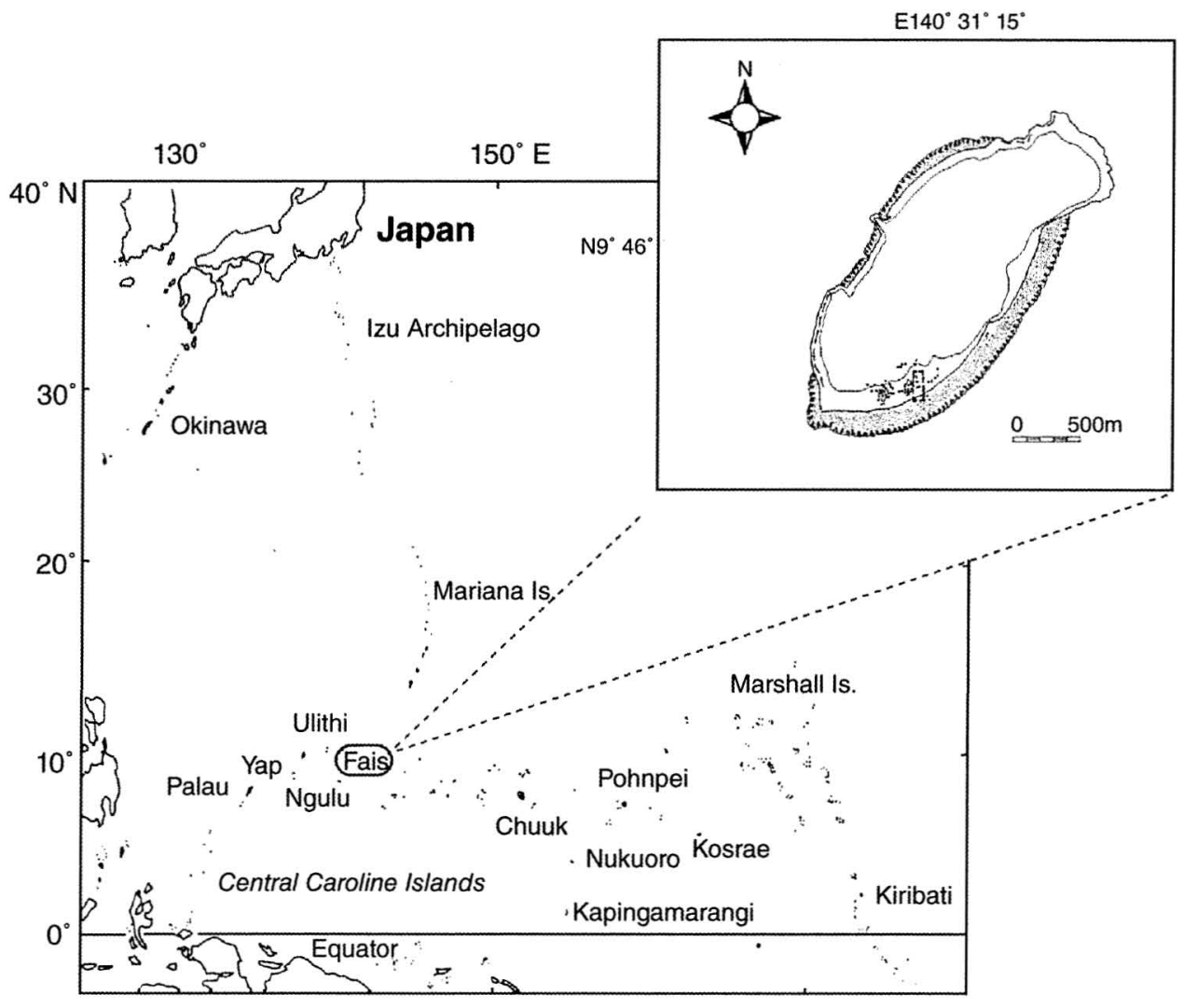

Fig. 1. Map of Fais Island. 


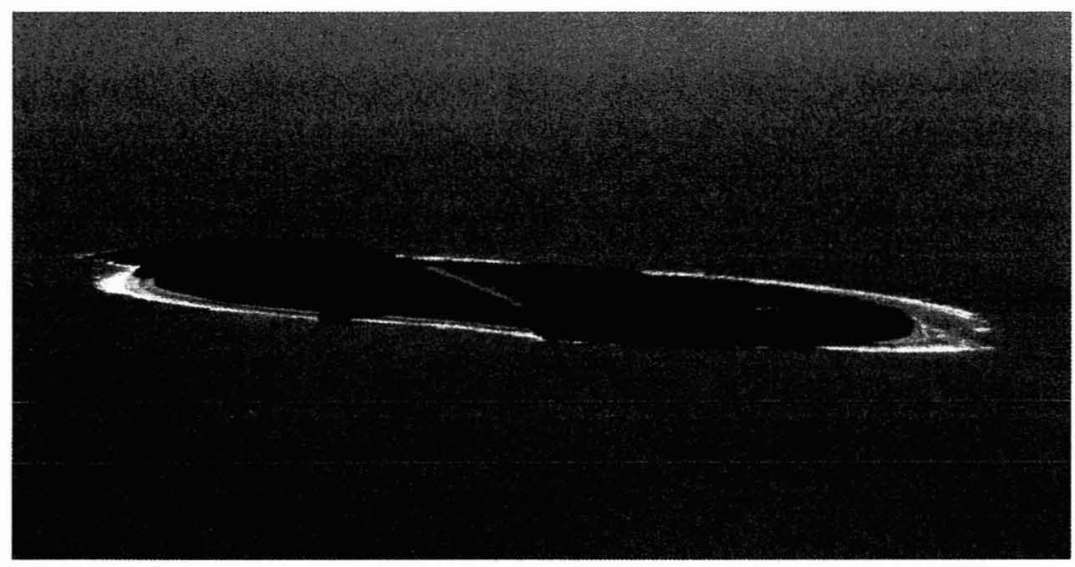

Fig. 2. Fais Island looking from northwest.

On the other hand, being a raised coral island, the outside of the reef sharply drops into the deep sea. Such a marine environment provides a different condition for fishing compared to that of atolls. Fish were caught mainly by angling, either from the reef top or the reef path. Sharks were caught in the open sea and were favored for food, in contrast to preferences by people living on the neighboring atolls.

The flat central plateau is about $20 \mathrm{~m}$ above sea level and was elevated by a steep slope from the flat coastal plain. The land area was rich in phosphate and had been mined by Germans and the Japanese in the early twentieth century. The rich soil environment on Fais allows the growth of lush vegetation and successful tobacco farming. The rainwater permeates the ground and does not form pools. Two wells, dug down to the freshwater lying on top of the seawater, were used in traditional society.

Fais has a tropical oceanic and moderately humid climate. The average mean temperature is $27^{\circ} \mathrm{C}$, and the annual rainfall is about $3000 \mathrm{~mm}$. The northeast windy season starts at the beginning of December and lasts until April or May. From the end of July to the end of September, the southwest wind prevails, which is a wetter season. Between these seasons, there are transitional seasons with calm days.

Subsistence on Fais today consists mainly of sweet potato, taro (Colocasia esculenta, Alocasia macrorrhiza), breadfruit, and coconut. Sweet potato was introduced by the Germans from Yap about 1850. Sweet potatoes and breadfruit are now the staple foods of Fais; however, these were not planted in abundance before the mid-nineteenth century. Krämer reported that taro and bananas were planted carefully and only a few breadfruit trees were observed (Krämer 1937:303). Tobacco grows well and has been an important exchange item in the sawei system, as this plant does not grow well on other atolls or on Yap Island. 


\section{Historical Background}

People on Fais Island speak the Nuclear Micronesian language. This language is widely spoken in the central Caroline Islands and Chuuk, and it is different from the Yapese language. A linguistic model of colonization in the central Caroline Islands indicates that Nuclear Micronesian speakers were dispersed from the southeastern Solomons and proceeded westward from Chuuk all the way to Tobi, lying about $450 \mathrm{~km}$ southwest from the main island of the Palau archipelago (Blust 1984; Shutler and Marck 1975). Fais is considered to be within this large wave of migration. With respect to the distribution of Nuclear Micronesian, language diversity is smaller in the west compared to the east. The eastern Caroline Islands are thus considered to have been settled earlier.

Most of the islands in the central Caroline Islands are atolls that have limited resources and are vulnerable to natural disaster. It is known that the inhabitants of such a resource-limited environment likely kept contact with nearby highlands, which are rich in natural resources. Such contacts were known for the central Caroline Islands. The exchange system between these atolls and Yap Island in the west is widely known as the sawei system (Alkire 1978). The people of Fais Island also joined this exchange system.

Besides such organized contacts with nearby coral islands and a high island, accidental contacts with other islands cannot be ignored. In 1664 alone, Father Andrea Serrano in the Philippines recorded 30 canoes that drifted from the Carolines. In 1697, Clain illustrated 29 Carolinians on Samar Island in the Philippines who had been blown to the west in two canoes. These Carolinians became lost when trying to return to Fais Island from Lamotrek, to which they had gone in two canoes (Hezel 1979).

\section{Archaeological Background}

Relatively little archaeological research has been carried out in the central Caroline Islands to date (Rainbird 2004). Craib surveyed on Ulithi atoll and did not find a deep stratified site. Only the late type of Yapese potsherds were found (Craib 1980). Descantes found some Yapese Plain potsherds from Ulithi that were dated to about 1400 B.P. (1998). Fujimura and Alkire carried out a test excavation on Faraulep, Woleai, and Lamotrek and found an early type of Yapese pottery (Fujimura and Alkire 1984; Dickinson 2006: 107). Dates associated with these potsherds were around A.D. 1200-1350. A pig tooth and a dog molar were also excavated and were dated to about the same period.

The archaeology in Yap, on the other hand, has revealed a little more than 2000 years of occupation history. Three types of pottery were made throughout this time span. The earliest CST (Calcareous Sand Tempered) pottery appeared from the earliest cultural phase followed by Plain pottery. The latest type of Laminated pottery appeared around A.D. 1450 and persisted into the historic era. The existence of prehistoric pigs and dogs is ambiguous (Intoh and Leach 1985). Paleoecological data, on the other hand, based on pollen and charcoal content analyses, indicates a longer habitation history on Yap, possibly about 3300 years (Dodson and Intoh 1999). Archaeological evidence is yet to be found for the earliest 1300 years of the sequence. 
Ngulu atoll, lying between Yap and Palau, was excavated by Takayama and Intoh in 1980. It was demonstrated that this small atoll had been inhabited for 1600 years. Pots were continuously imported from Yap and Palau throughout its occupation history (Intoh 1981). An excavated dog skeleton indicated that dogs once existed on Ngulu where no dogs were kept in the historic era. This was the only evidence of prehistoric dog found in western Micronesia until some dog remains were excavated on Fais (Intoh and Shigehara 2003).

\section{RESEARCH DURING THE I99I AND I994 FIELD SEASONS}

In 1991, I carried out archaeological research on Fais with the following goals:

1. to examine the process of site formation and landscape change caused by human activities on the island (the advantage of excavating Fais being it is a raised coral island);

2. to compare the subsistence strategies of the Fais population with the surrounding atolls in the central Caroline Islands; and

3. to test the linguistic model of human settlement in the central Caroline Islands.

Among the three traditional villages extending along the southern coastal plain of Fais, the eastern village, Faliyow, was selected for the archaeological research. Five excavation units were set out in different landscapes, from beach to the coastal plain, and to the inland slope. A total of $28 \mathrm{~m}^{3}$ was excavated.

An inland slope site (FSYE) did not yield many archaeological remains while the FSFA site (FSFA-1 and 2) and FSPO site (FSPO-1) on the coastal flat site yielded a rich cultural deposit. The depth of these sites was about $1.5 \mathrm{~m}$. The early dates, about 160 B.C. 550 A.D. [NUTA2167] from layer 6A and A.D. $100 \sim 400$ [NZ7885] from layer 5 were obtained from the FSFA-2 site. A number of cultural remains, mainly CST potsherds imported from Yap island were excavated from this layer. The large error ranges of these dates, however, provide only an ambiguous time span for the colonization date of the island.

In contrast, FSPO-2, the beach site, showed a deep stratified cultural deposit, more than $2.7 \mathrm{~m}$. Due to limited research time, the excavation had to terminate when the excavation reached layer 13, a layer that seemed to be culturally sterile, although it contained one rim sherd at the top, together with some rat bones. Layer 12 was dated to about A.D. 370 830 [NUTA2347]. Because this date was not as early as the dates obtained from the inland FSFA site, another excavation was needed to investigate the bottom of the cultural deposit in the coastal region.

A variety of artifacts including a number of imported potsherds were excavated during the 1991 research season. The vertical distribution pattern of the three types of Yapese pottery (CST, Plain, and Laminated) indicates that pottery was constantly brought in from Yap.

Four cultural phases were tentatively proposed based on 12 charcoal radiocarbon dates and pottery types, as indicated below (Intoh and Shigehara 2003) (Table 1):

Phase I: A.D. 1 400 (CST pottery)

Phase II: A.D. 400 800 (mainly Plain pottery)

Phase III: A.D. 800 1400 (mixture of Plain and Laminated)

Phase IV: A.D. 1400 historic time (mainly Laminated) 
Table i. Tentative Cultural Phases on the Basis of Previous Research (INTOH AND SHIGeHARA 2004)

\begin{tabular}{|c|c|c|c|c|c|}
\hline CULTURAL RHASE & FSYE & FSFA-I & FSFA-2 & PO-I & $\mathrm{PO}-2$ \\
\hline $\begin{array}{l}\text { IV } \\
\text { (A.D. 1400-historic) }\end{array}$ & 1 & 1 & 1 & 1 & $\begin{array}{l}1 \\
2\end{array}$ \\
\hline III & & 2 & 2 & 2 & 3 \\
\hline (A.D. 800-1400) & & & 3 & $\begin{array}{l}3 \\
4\end{array}$ & $\begin{array}{l}4 \\
5 \\
6 \\
7 \\
8\end{array}$ \\
\hline II & & 3 & 4 & & 9 \\
\hline (A.D. $400-800$ ) & & 4 & & & $\begin{array}{l}10 \\
11 \\
12 \\
13\end{array}$ \\
\hline I & & & $\begin{array}{l}5 \\
6\end{array}$ & & \\
\hline
\end{tabular}

The existence of dog and pig during Phase II is secure, but the possibility during Phase I is yet to be confirmed.

Rats were plentiful among the faunal remains excavated. These existed on the island from the earliest level to the present. These rats were the Asian version of Rattus rattus (White and Flannery n.d.) that are distributed mainly in Southeast Asia. This variety was different from that which was brought to Melanesia or Polynesia by the Austronesian-speaking population. This strongly indicates that the human dispersal to Fais was made from the west rather than the south. This contradicts the scenario suggested by linguistic studies.

Some excavated material reveals interregional contacts. One example is the pearl-shell lure shank with a very distinct head shape. This was made to have strings tied around the head knob without using notches or holes. Similar types of lure shanks have been reported from the Marshalls and the Solomons. Another example is the bone lure point. This specimen does not have any holes but has two barbs at the base for tying to a shank. The closest type is found in the ethnographic collections from the Solomons. These findings may indicate some cultural contacts between Fais and the Solomon Islands (Intoh 1996a). Dates for these artifacts are around A.D. 450-750 (Phase II) and around A.D. 1050-1400 (Phase III), respectively.

In 1994, a burial ground near the western end of the current village area was surveyed and excavated. The area served as a cemetery before missionaries changed the interment customs on Fais. A total of 11 burials were excavated, dating approximately A.D. $1300 \sim 1500$.

A number of goods were associated with burials, mostly small beads made of shell and glass, a number of shell bracelets made of Trochus and Tridacna shell, and a shell fishhook. Elemental composition of the prehistoric glass beads was analyzed by an X-ray microanalyzer. It became clear that the assemblage has a mixed 
origin. Two kinds of glass beads, high in lead content, were shown to be Chinese in origin, while one kind with a characteristic decorative pattern was shown to be of Venetian origin. The possibility that the late prehistoric Fais islanders had access to such foreign glass products via the Philippines was proposed (Intoh 1996b).

\section{RESEARCH DURING THE 2005 FIELD SEASON}

The third phase of research on Fais Island began on 21 November 2005, and ended about three weeks later. The objectives of this research were:

1. excavating the northern side of the island in order to test the extension of the habitation area;

2. excavating the southern coastal deposit, where only a small test unit was opened during the previous phase of research, in order to understand site formation process and colonization history;

3. more closely examining the distribution pattern of domesticated animals, with a finer sequence of carbon dates; and

4. reconstructing the colonization scenario based on the newly acquired results.

A total of 12 excavation units $\left(12 \mathrm{~m}^{2}\right)$ were set out and excavated; three were on the northern coast and nine on the southern coast. As a detailed excavation report is under preparation (Intoh and Ono n.d.), this paper describes mainly the Powa site (FSPO) on the southern coast near the central part of the present village area. This site was excavated during the 1991 phase of research (FPO-2) and revealed a deep cultural deposit. The size of the research unit then was only $1 \times 1.5 \mathrm{~m}$, due to limited research time. It was further reduced to $1 \times 1 \mathrm{~m}$ as the excavation proceeded. Despite such a deep cultural deposit, the date obtained from this square was not very old compared to the date from the inner site (FSFA). It was thus necessary to test whether another cultural layer lay beneath. The Powa site was therefore reexamined by setting out two $1 \times 2 \mathrm{~m}$ squares (FSPO-3, 4 and 8, 9 being three meters apart against the coastline) about $5.7 \mathrm{~m}$ east of FSPO-2. A total of 12 cultural layers were recognized at both sites and the lowest layer went down to over $3.3 \mathrm{~m}$ (Fig. 3).

Several $u m$ (earth oven) features were recognized with clusters of burned coral gravels. Some kind of house structure was also uncovered, associated with packed layers of small, water-worn, white coral beach cobbles. The spreading of beach cobbles is still practiced around households in villages on the island.

A very dark, packed sandy soil layer was detected at layers 4, 6, and 9. Occasional patchy beach sand pockets were observed in some layers but were not as persistent as to form a layer. Since no sterile layer was found between the bottom layer and the top layer, the island seems to have been occupied constantly since the initial colonization.

\section{DATING}

A considerable amount of charcoal samples were collected from almost all the cultural layers. A total of eight charcoal samples were selected and submitted to 


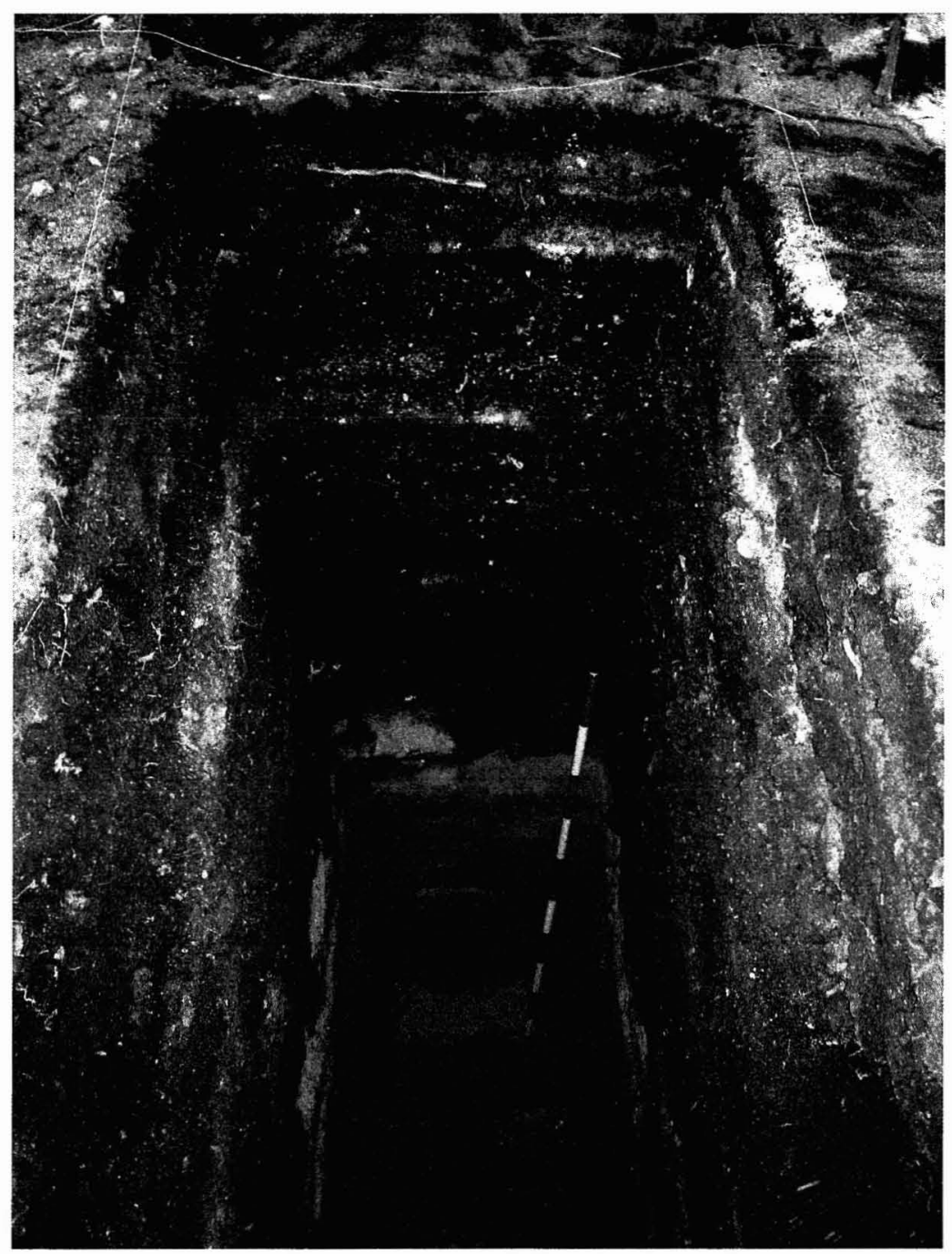

Fig. 3. South section of the FSPO-4 site (the pole is $2 \mathrm{~m}$ long).

the Beta Analytic Radiocarbon Dating Laboratory for AMS radiocarbon dating. All of these samples were collected in situ and are believed to have secure stratigraphic associations. Calibrated ages are reported at two standard deviations $(\delta)$.

The results fit in good chronological order as shown in Table 2 and Figure 4. The earliest layer (layer 12) is dated by two samples (Beta-213060 and 213061) as $1720 \pm 40$ B.P. (A.D. $230 \sim 410$ ), and $1700 \pm 40$ B.P. (A.D. $240 \sim 420$ ), respectively. These are within the same range and are considered as the initial habitation period of Fais Island. A number of cultural remains such as Tridacna sp. shell adzes, shell bracelets, and shell beads were obtained, in addition to a small amount of potsherds and faunal remains. 
Table 2. Radiocarbon Results

\begin{tabular}{lcccccc}
\hline $\begin{array}{l}\text { LAB. \# } \\
\text { (BETA-) }\end{array}$ & SITE & LAYER & $\begin{array}{c}\text { DEPTH } \\
(\mathrm{cm})\end{array}$ & SAMPLE & $\begin{array}{c}\text { CONVENTIONAL } \\
\text { B.P. }\end{array}$ & $\begin{array}{c}\text { CALIBRATED } \\
\text { (95\% PROBABILITY)* }\end{array}$ \\
\hline 213060 & FSPO-4 & 12 & -280 & Charcoal & $1720 \pm 40$ & A.D. $230(340) 410$ \\
213061 & FSPO-4 & 12 & -258 & Charcoal & $1700 \pm 40$ & A.D. $240(370) 420$ \\
213062 & FSPO-3 & 11 & -220 & Charcoal & $1560 \pm 40$ & A.D. $410(530) 600$ \\
221149 & FSPO-3 & 10 & -181 & Charcoal & $1550 \pm 40$ & A.D. $420(530) 610$ \\
221150 & FSPO-8 & 10 & -194 & Charcoal & $1510 \pm 40$ & A.D. $440(560) 640$ \\
213063 & FSPO-3 & 8 & -136 & Charcoal & $1360 \pm 40$ & A.D. $630(660) 710$ \\
213064 & FSPO-3 & 6 & -90 & Charcoal & $770 \pm 40$ & A.D. $1200(1270) 1290$ \\
\hline
\end{tabular}

* After Stuiver et al. 1998.

One sample from layer 11 (Beta-213062) and two samples from layer 10 (Beta221149 and 221150 ) were dated as $1560 \pm 40$ B.P. (A.D. $410 \sim 600$ ), $1550 \pm 40$ (A.D. 420 610), and $1510 \pm 40$ B.P. (A.D. 440 640), respectively. These dates overlap considerably and can be combined in the same cultural phase. This period is characterized with a large number of Yapese CST potsherds and some Plain potsherds (Fig. 5). A number of shell artifacts such as Tridacna sp. shell adzes, shell bracelets, shell beads, etc., were obtained. Considerable amount of faunal remains were also excavated. The significant point here is that pig and dog remains began to appear in layer 10 (Fig. 6).

Layers 9 and 8 were also rich in potsherds and faunal remains. The date for layer 8 was $1360 \pm 40$ B.P. (A.D. 630 710) (Beta-213063). The number of Plain potsherds increased from layer 9 to layer 8 and became dominant in layer 7 . The number of CST potsherds was almost equal in these layers. The use of turtle carapace for blade tools and single fishhooks increased suddenly in these layers. Other artifacts included Tridacna shell adzes, shell ornaments, worked coral, and perforated dog and shark teeth. Cassis sp. shell adze/chisels appeared in layer 7.

Layer 6 was dated as $770 \pm 40$ B.P. (A.D. 1200 1290). From this layer, the number of potsherds decreased considerably. Laminated potsherds first appeared from layer 6 and were continuously found through to layer 1, while Plain and CST potsherds disappeared from layer 4 (Fig. 5). The variation of material culture did not change much except that Cassis sp. shell scrapers appeared in this layer.

Four cultural phases proposed by the previous research (Table 1) may be examined against the new data set. Most of the new dates seem to fit these cultural phases, but some revisions are required. The earliest cultural phase (I) was set out as A.D. $1 \sim 400$ as a result of the 1991 research. This was based mainly upon the dates obtained from a little inland site (FSFA).

The dates obtained from layer 12 of the PO-4 site in this recent research are clearly earlier than Phase II and can be identified as Phase I. The time range for Phase I at PO-3 4 is shorter compared to the range obtained from the FSFA site. It would be reasonable to set the range as A.D. 200 400 for Phase I at least at the Powa site. An earlier beginning for Phase I at the FSFA site is still plausible.

The other cultural phases were identified as shown in Table 3. Layers 8 to 11 form Phase II, layer 6 forms Phase III and layers 3 to 1 form Phase IV. Layers 7 and 4 do not have $\mathrm{C}^{14}$ dates and are yet to be classified. 


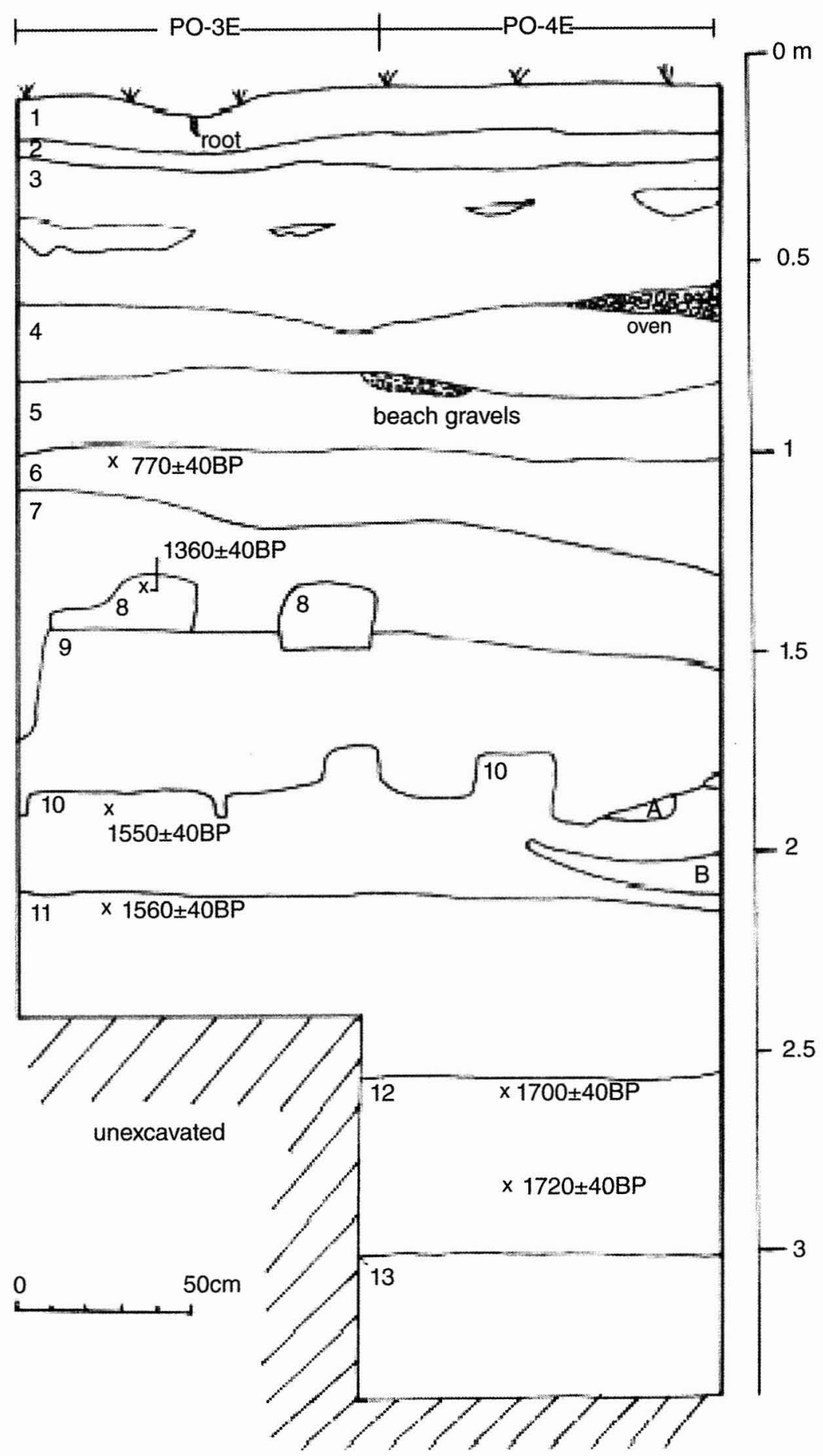

Fig. 4. Stratigraphy of the FSPO-3 and 4 sites (east wall). 


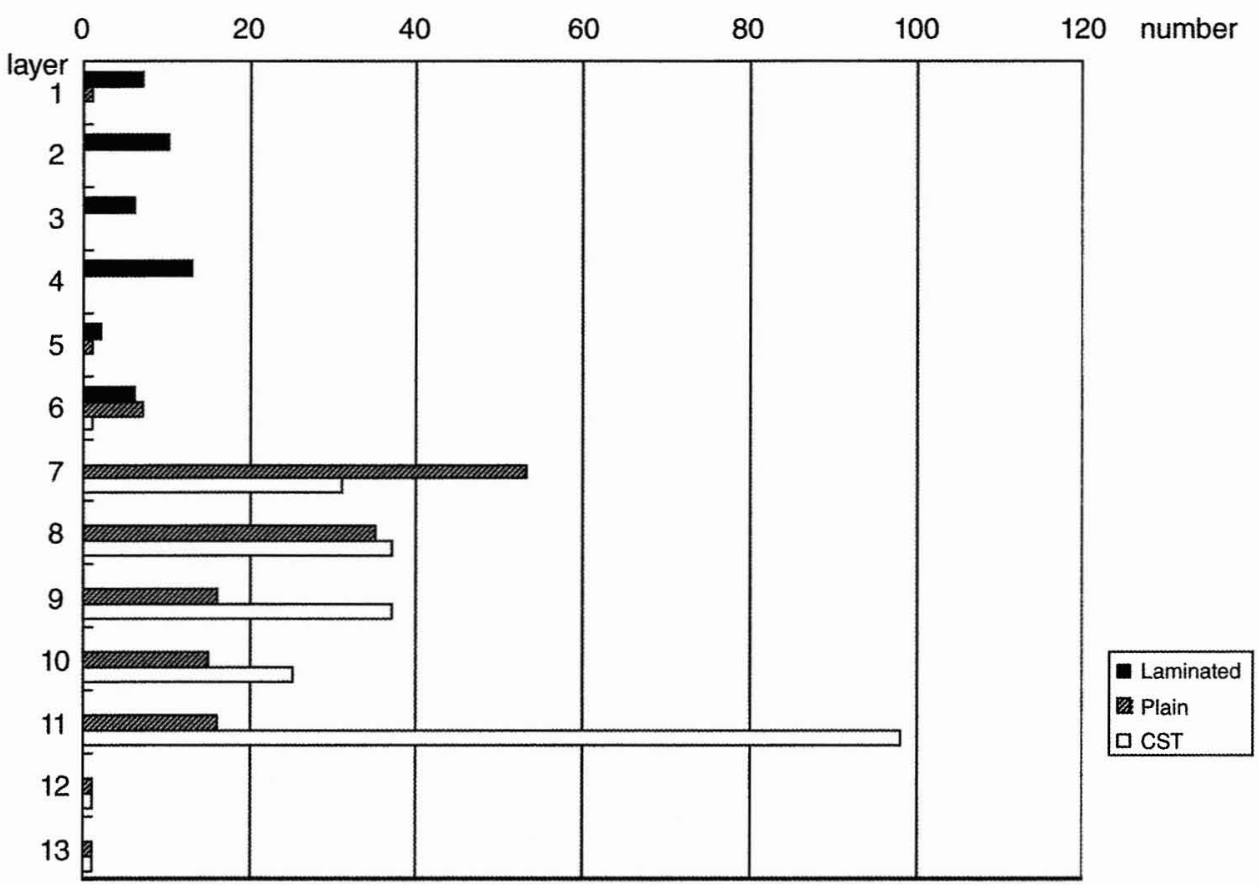

Fig. 5. Distribution of three types of Yapese potsherds excavated from the FSPO site.

dog and pig bones excavated from FSPO-3,4,8 and 9

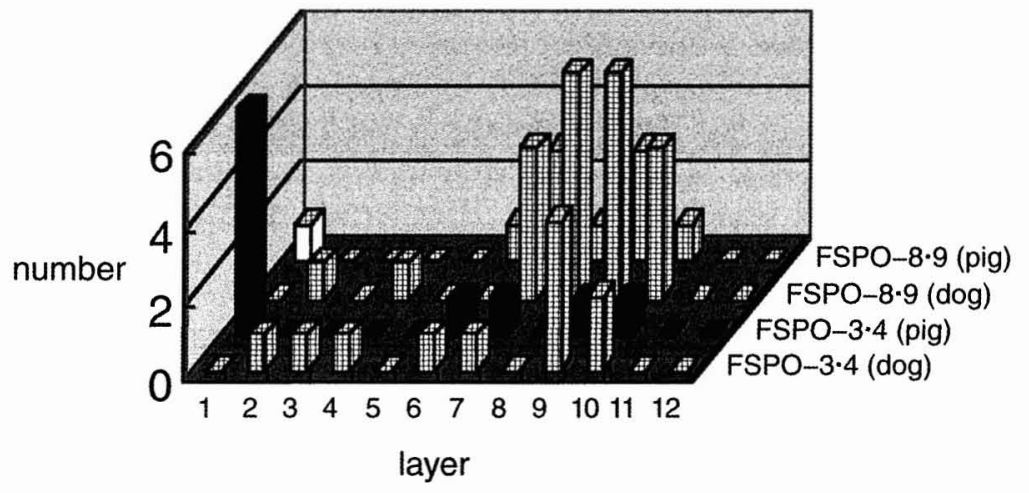

嘈 FSPO-3.4 (dog)

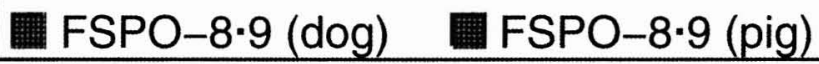

Fig. 6. Distribution of dog and pig bones in the FSPO site, Fais Island. 
Table 3. Revised Cultural Phases for Fais Island based on 2005 Research

\begin{tabular}{ccr}
\hline CULTURAL PHASE & & PO-3 9 \\
\hline IV & A.D 1400-historic & 1 \\
& & 2 \\
III & A.D. $800-1400$ & 3 \\
II & A.D. $400-800$ & 6 \\
& & 8 \\
& & 9 \\
I & A.D 200-400 & 10 \\
& & 11 \\
\end{tabular}

\section{EXCAVATED MATERIALS}

Considerable amount of faunal remains were excavated. The majority included fish, rats, and marine turtles together with some mammals and birds. Mammal bones, except for rats, were examined by Dr. Nobuo Shigehara. Preliminary results are shown in Figure 6. A number of pig, dog, and porpoise remains were identified down to layer 10. This confirms that pig and dog were kept in the prehistoric Fais society fairly continuously. The earliest evidence came from layer 10 which was dated as $1550 \pm 40$ B.P. (A.D. 420 610). Judging from the dates obtained from layer 11 (A.D. 410 600), dogs and pigs unquestionably existed during Phase II. The earliest evidence obtained in the previous research was from FSFA site (Phase I). The antiquity of domesticated animals on Fais will be discussed further below.

Rat remains were found in abundance from all the layers down to layer 12 . This shows clearly that rats came to Fais with the earliest colonizers and survived into the historic era.

A total of about 500 potsherds were uncovered (in which about 65 were not from the Powa site). Based on the color, texture, breakage pattern, and other features, the majority of these sherds were identified as Yapese while some were identified as Palauan (Fig. 7a). Three types of typical Yapese pottery were identified (Intoh and Leach 1985). The vertical distribution of these three types, CST, Plain, and Laminated, is shown in Figure 5. The earliest type, CST, was followed a little later by Plain, and then by Laminated. This chronological order was also recognized at the FSFA site during the 1991 research and indicates the continuous prehistoric contacts with Yap. A number of reddish potsherds were identified as the excavation continued to deeper levels. Some of these were recognized as Palauan, on the basis of their dark core. More detailed analyses are in progress.

Besides pottery, a variety of artifacts made of shell, coral, bone, and turtle carapace were excavated (Table 4). The same distributional pattern was observed as described in the section above on dating. The variation of artifacts is almost the same as that obtained during the 1991 research.

A variety of Tridacna sp. shell adzes were found (Fig. 7b) throughout the sequence. Most of these were made of Tridacna maxima (small giant clam) or T. squamosa (scaled clam), with some thick heavy ones made of Tridacna gigas (giant clam). On the other hand, Cassis sp. adze/chisels (Fig. 7c) appeared later, 


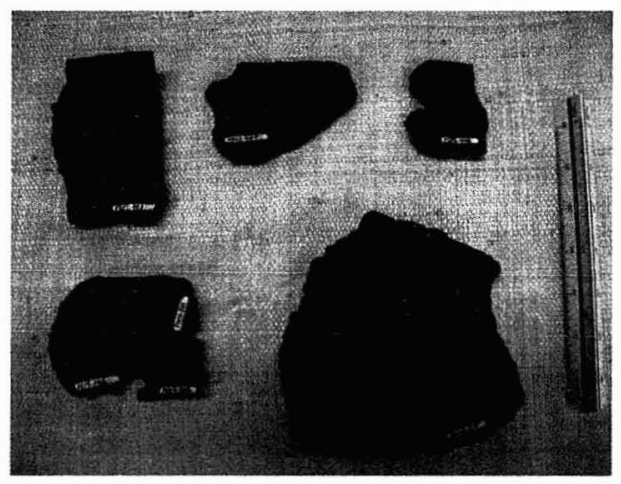

a

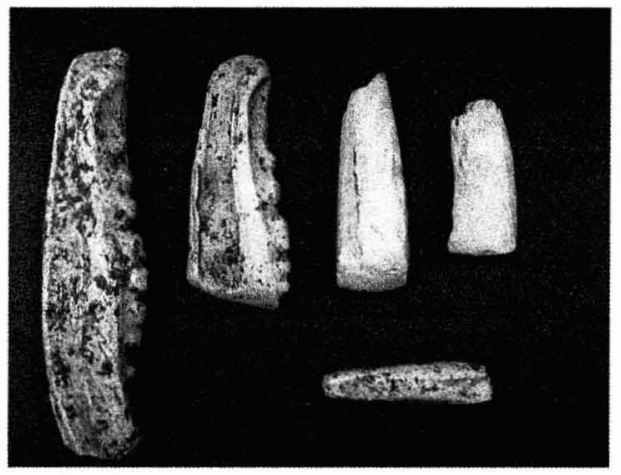

c

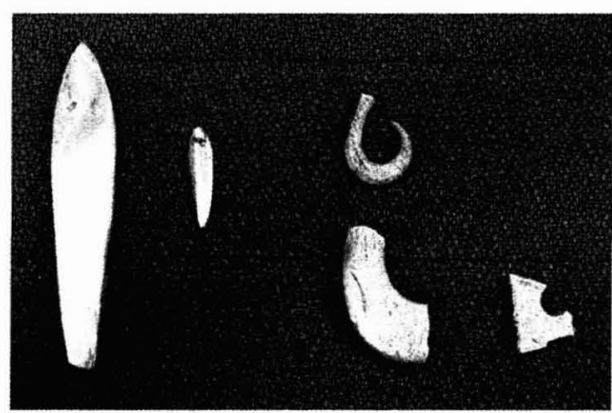

e

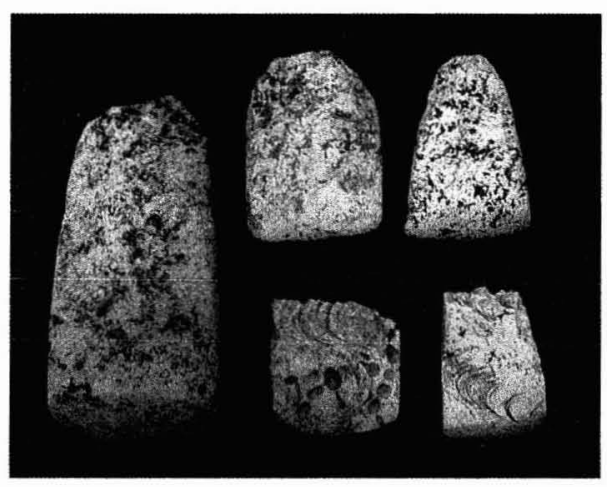

b

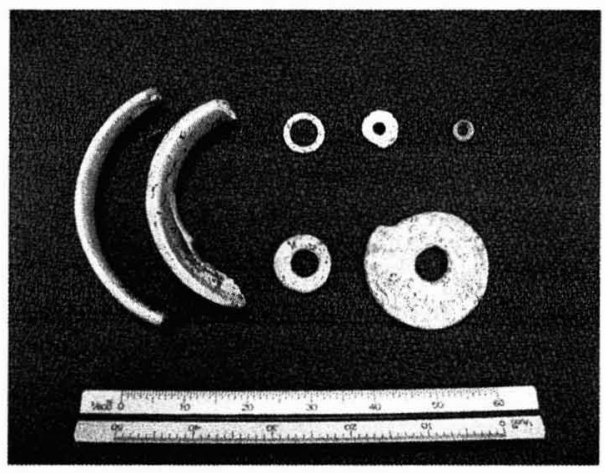

d

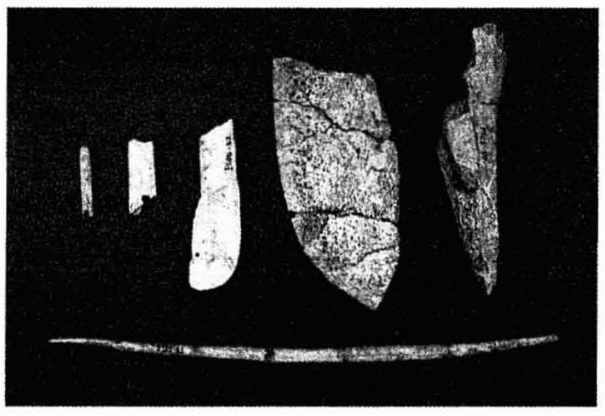

f

Fig. 7. Excavated artifacts-a: Yapese potsherds; b: Tridacna shell adzes; c: Cassis shell adze/chisels; $\mathrm{d}$ : shell beads, disc and bracelets; e: trolling lures, one-piece fishhook and unfinished ones; f: bone and turtle carapace artifacts. 
Table 4. Number of Artifacts Excavated from FSPO (3, 4, 8 and 9) and Other Sites and the Earliest Layer Found

\begin{tabular}{lrcr}
\hline ARTIFACT TYPE & FSPO & OTHER SITES & LOWEST LAYER \\
\hline Pottery disc & 1 & 0 & 7 \\
Hammer stone & 1 & 0 & 8 \\
Perforated arc shell & 1 & 0 & 7 \\
Perforated pearlshell & 0 & 1 & 1 \\
Shell adze/chisel (Cassis sp.) & 4 & 3 & 6 \\
Shell adze (Tridacna sp.) & 18 & 8 & 12 \\
Shell bead & 10 & 3 & 12 \\
Shell disc (large) & 2 & 1 & 4 \\
Shell ring & 16 & 1 & 11 \\
Shaped spondirus shell & 1 & 0 & 7 \\
Small shell ring (unfinished) & 6 & 0 & 11 \\
Small trolling lure-shaped pendant? & 1 & 0 & 4 \\
Spider shell scraper (rough out) & 1 & 0 & 6 \\
Trolling lure (Trochus sp.) & 1 & 0 & 12 \\
Worked pearlshell & 5 & 0 & 9 \\
Adze-shaped coral & 0 & 1 & 8 \\
Coral file & 2 & 0 & 9 \\
Worked sea urchin & 4 & 0 & 9 \\
Bone needle & 1 & 0 & 9 \\
Fishhook (turtle carapace) & 5 & 0 & 8 \\
Fishhook tab & 1 & 0 & 7 \\
Perforated dog/pig tooth & 1 & 0 & 8 \\
Perforated porpoise (?) tooth & 1 & 0 & 11 \\
Perforated shark tooth (1 hole) & 3 & 0 & 10 \\
Worked bone & 10 & 1 & 2 \\
Worked turtle bone (chisel?) & 22 & 2 & \\
Worked turtle carapace (blade) & 1 & 0 & \\
Glass bead & & & \\
\hline & & 0 & \\
\hline
\end{tabular}

in Phase 3 (Fig. 7c). This late appearance was also observed during the 1991 research. The Cassis sp. knife/scrapers made of the body part of shells seem to have appeared later, too.

A considerable number of shell ornaments were also excavated (Fig. 7d). These included shell rings of various sizes (made of Tridacna sp., Trochus sp., and Conus sp.), shell beads (Conus sp.), and shell pendants/ear ornaments (pearl shell and Spondylus sp.). The arm rings obtained from Phase I were made of Trochus sp. and have triangular cross sections.

Fishhooks include lures for trolling and single hooks for angling. Only two trolling lures were found (Fig. 7e, two from the left). These were made of either mother-of-pearl or Trochus sp. shell. Strangely, one of these is very small $(25 \mathrm{~mm}$ long and $5.5 \mathrm{~mm}$ wide). Although it has a hole through the head part, this hook may not have functioned as a fishhook, but as a breast or ear ornament. The other lure was found in layer 5 and has a reconstructed length of about $8 \mathrm{~cm}$. The head part is a triangle in cross section and has a perforation for a fish line. This type of lure head is widely found in Micronesia and east to the Marshalls.

On the other hand, single fishhooks were made of turtle carapaces. The amount of excavated fishhooks was much smaller compared to those found in 
1991. Only a few broken finished fishhooks were found (Fig. 7e). Some unfinished fishhook tabs indicate that fishhooks were being made around the site.

A number of worked bones were found, such as one bi-pointed bone needle $(17.5 \mathrm{~cm}$ long), several thin and narrow tools with a hole, and some bone chisellike tools (Fig. 7f). Many of these were turtle carapaces with sharp blades (Fig. 7f, second from the right). The other artifacts included a hammer stone, worked mother-of-pearl shell, perforated teeth (dog, porpoise and shark), perforated sea urchin, small pottery disc, and coral files. Historic artifacts, such as glass, modern ceramics, iron pieces, plastic, etc. were mostly found in layer 1.

\section{DISCUSSION AND CONCLUSION}

A deep archaeological deposit on Fais Island extends along part of the southern coast. Several small excavation units opened on the northern coast and eastern edge of the village area exhibited shallow cultural deposits. The area with deep cultural deposit (over $3 \mathrm{~m}$ ) seems to be limited to the central part of the current villages. Rapid sand deposition was observed, particularly for Phases I and II at the Powa site. Some dark, packed, sandy soil layers are due to charcoal particles mixed in the soil, resulting from dynamic human activities associated with fire, such as agricultural clearing and domestic fires. It seems that the current village area along the southern coast was used for the major settlement area during the last 1800 years of occupation.

The 2005 excavation provides a secure chronology for Fais Island. Four cultural phases proposed from the 1991 research were confirmed except for the initial phase. Two comparable dates obtained from the lowest layer indicate that the initial colonization seems to have been made around A.D. 200 400. This time range is a little shorter compared to the 1991 cultural phase (A.D. 1 400). The narrower range for Phase I seems more realistic, at least at the Powa site. This time range for the initial settlement is most securely dated among the coral islands in the central Caroline Islands.

The speed of sediment deposition was rapid during Phase I and II at the PO-3 and 4 sites, about $36 \sim 38 \mathrm{~cm} / 100$ years. It might well be the result of the soil erosion following human colonization and the impact on island vegetation. Such phenomena are increasingly reported from many islands in Oceania (e.g., Dodson 1992; Kirch and Hunt 1997).

A variety of artifacts were excavated, exceeding the amount obtained in 1991. It is notable that Tridacna sp. shell adzes had been used since the earliest phases of settlement while Cassis sp. shell adze/chisels appeared later in the cultural sequence. No Terebra/Mitra sp. adze/chisel shells, which have a wide distribution in Micronesia (Intoh 1981b), were found. These were considered Micronesian adzes by researchers working in Melanesia (see Intoh 1999). This could have been due to environmental factors, although this was not found in Tobi where some migrants from Fais settled (Intoh and Ono 2007).

Domesticated animals were found in early cultural deposits. Pig and dog remains are securely dated to Phase II (A.D. 400 800). The possibility of earlier dates for these animals still remains, due to the evidence from the 1991 research. Nonetheless, this is still the earliest evidence for prehistoric pigs in Micronesia. The long term care of domesticates, particularly pigs, has been considered difficult 
on such a small coral island (see Kirch 2000). The case of Fais may require reconsideration of this issue.

Continuous cultural contacts with Yap are obvious from the excavated potsherds throughout the culture sequence. Inter-island contacts with resource-rich high islands were of particular significance to the coral islanders. This was not only for obtaining mineral resources but also for assurance against natural hazards. The living strategy on Fais Island was thus twofold: intensive agricultural activities, and keeping external contacts with resource-rich islands. It is not, however, clear and is beyond the scope of the present discussion if such cultural contacts were performed through a sophisticated exchange system known as sawei which persisted into the historic era.

Finally, colonization of Fais Island needs to be mentioned. The date of A.D. 200 400 for the initial colonization period was much earlier than the model proposed by Alkire (1978). If the linguistic model indicating movement from the east is considered, migration from the eastern Caroline high islands to Fais was made only 200 years following the settlement of Chuuk or Pohnpei. Such early dates were not found on the surrounding atolls. If the east-to-west migration model is accepted, Fais was among the earliest islands to be settled. Alternatively, it is also plausible that Fais was colonized directly from the homeland of Nuclear Micronesia where dogs and pigs were likely kept. In this case, contact with Yap could have been made soon after the colonization.

Given the visible evidence of cultural contact with Yap from the earliest stage, together with the introduction of Asian rats, it is still plausible that some human movements were made from Yap to Fais (Intoh 1997). It is likely that the Fais Island people were rather active explorers, in contrast to descriptions in some historic records. A set of domesticated animals kept on Fais by Austronesianspeaking peoples cannot be explained without having direct contacts with Melanesia or Island Southeast Asia.

If the first settlers were from Yap, how can the contradiction with language data be explained? It is plausible to consider that the migrants from Yap represented a very small population (cf. Rainbird 2004). However, a large-scale impact upon the natural environment at Phase I (Intoh 2007) may present contradictory evidence. In Phase III, another rapid sequence of sedimentation took place. Having a new group of migrants from the east at this phase (A.D. 800 1400) is conceivable. Future studies will need to further consider the crucial issue of language replacement in comparison to patterns obtained from archaeological data.

\section{ACKNOWLEDGMENTS}

The 2005 research was carried out as a part of the project "Selective use of natural resources and symbolization" funded to Intoh by the Ministry of Education, Science, Sports and Culture, Grant-in-Aid for Scientific Research on Priority Areas. Research permits were provided by James Lucan, Yap HPO Officer and Luis, Chief of Fais Island, to whom I am grateful. Among many individuals involved in the 2005 research, I owe many thanks to Rintaro Ono, who served as a co-researcher, Don Rubinstein who shared his anthropological knowledge of Fais as always, and to Dr. Nobuo Shigehara who provided his knowledge on mammal remains. Last, but not least, I would like to express my sincere appreciation to the people of Fais who always support me with enthusiasm in my efforts to understand their ancient history. I am grateful to two anonymous referees for their critical reading of the first draft. All the errors, however, are my own. 


\section{REFERENCES CITED}

AlKire, W. H.

1978 Coral islanders. Arlington Heights: AHM Publishing.

BLust, R.

1984 Malaita-Micronesian: An eastern Oceanic subgroup? The Journal of the Polynesian Society 93(2): 99-140.

Craib, J. L.

1980 Archaeological survey of Ulithi Atoll, Western Caroline Islands. Monograph of Pacific Studies Institute 1. Agana: Pacific Studies Institute.

Descantes, C.

1998 Integrating archaeology and ethnohistory: The development of exchange between Yap and Ulithi, Western Caroline Islands. Ph.D. diss. Department of Anthropology, University of Oregon.

Dickinson, W. R.

2006 Temper sands in prehistoric Oceanian pottery: Geotectonics, sedimentology, petrography, provenance. Special Paper, 406. Boulder: The Geological Soceity of America.

DODSON, J., ED.

1992 The naive lands: Prehistory and environmental change in Australia and the Southwest Pacific. Melbourne: Longman Cheshire.

Dodson, J. R., And M. InTOH

1999 Prehistory and palaeoecology of Yap, Federated States of Micronesia. Quaternary International 59:17-26.

Fujimura, K., and H. W. Alkire

1984 Archaeological test excavations on Faraulep, Woleai, and Lamotrek in the Caroline Islands of Micronesia, in Caroline Islands archaeology: Investigations on Fefan, Faraulep, Woleai, and Lamotrek: 65-149, ed. Y. H. Sinoto. Pacific Anthropological Records 35. Honolulu: Bishop Museum Press.

Hezel, F. X.

1979 Foreign ships in Micronesia: A compendium of ship contacts with the Caroline and Marshall Islands, 1521-1885. Saipan: F. J. Hezel and Trust Territory Historic Preservation Office.

INTOH, $M$.

1981 The shell artefacts in Oceania, in The Nagura Shell Mounds, Okinawa Cultural Research Report 37:103-159. Okinawa: Department of Education, Okinawa Prefecture Government (in Japanese).

1993 Archaeological research on Fais Island: Preliminary report, in Cultural Anthropological Research on Historic Media in the Caroline Islands: 69-111, ed. K. Komatsu. Osaka: Committee for Micronesian Research 1991, Osaka University.

1995 The acceptance of the outside world on Fais Island in Micronesia: 1994 research. Preliminary report submitted to the Historic Preservation Office, Yap State, Federated States of Micronesia.

1996a Multi-regional contacts of prehistoric Fais Islanders in Micronesia. Bulletin of the IndoPacific Prehistory Association 15:111-117.

19966 Analyses of glass artefacts excavated from the prehistoric cemetery of Fais Island. Research Reports of Composite Research Unit of Tokai University 20:241-245 (in Japanese).

1997 Human dispersals into Micronesia. Anthropological Science 105(1): 15-28.

1999 Cultural contacts between Micronesia and Melanesia, in Pacifique de 5000 a 2000 avant le Present: Supplements a l'Histoire d'une Colonisation: 407-422, ed. J.-C. Galipaud and I. Liley. Paris: Éditions de IRD (Institut de Recherche pour le Developpement).

2007 Historical ecology of Fais Island, Micronesia. Paper presented at 21st Pacific Science Congress, Okinawa.

INTOH, M., AND W. R. Dickinson

2002 Prehistoric pottery movements in western Micronesia: Technological and petrological study of potsherds from Fais Island, in Fifty years in the field: Essays in honour and celebration of Richard Shutler Jr's archaeological career: 123-134, ed. S. Bedford, C. Sand, and D. Burley. New Zealand Archaeological Association Monograph 25. Auckland: New Zealand Archaeological Association.

INTOH, M., AND B. F. LEACH

1985 Archaeological investigations in the Yap Islands, Micronesia: First millennium B.P. to the present day. BAR International Series 277. Oxford: BAR. 
INTOH, M., AND R. ONO

2007 Reconnaissance archaeological research on Tobi Island, Palau. People and Culture in Oceania 22:53-83.

n.d. Archaeological research on Fais Island, 2005 field season. MS report to be submitted to the HPO of Yap State, FSM.

InTOH, M., AND N. Shigehara

2003 Prehistoric pig and dog remains from Fais Island, Micronesia. Anthropological Science 112:257-267.

$\mathrm{KIRCH}, \mathrm{P}$.

2000 Pigs, humans and trophic competition on small Oceanic islands. Australian archaeologists: Collected papers in honour of Jim Allen, 1:427-439.

KirCh, P., AND T. L. HunT, EDS.

1997 Historical ecology in the Pacific Islands: Prehistoric environmental and landscape change. New Haven: Yale University Press.

KRÄMER, A.

1937 Zentralkarolinen. Halbband 1: Lamotrek-Gruppe-Oleai-Feis. Ergebnisse der SüdseeExpedition 1908-1910. Hamburg: Friederichsen.

LEE, A. L.

2006 The morphological examination of the human skeletal remains from Fais Island, Federated States of Micronesia. M.Sc. thesis. Laboratory of Physical Anthropology, Kyoto University.

RAINBIRD, P.

2004 The archaeology of Micronesia. Cambridge World Archaeology. Cambridge: Cambridge University Press.

Shutler, R. J., AND J. C. Marck

1975 On the dispersal of the Austronesian horticulturalists. Archaeology \& Physical Anthropology in Oceania 10(2): 81-113.

Steadman, D. W., and M. Intoh

1994 Biogeography and prehistoric exploitation of birds from Fais Island, Yap State, Federated States of Micronesia. Pacific Science 48(2):116-135.

Stuiver, M., P. J. Reimer, E. Bard, J. W. Beck, G. S. Burr, K. A. Hughen, B. Kromer, G. Mccormac, J. V. D. Plicht and M. Spurk

1998 INTCAL98 radiocarbon age calibration, 24000-0 cal BP. Radiocarbon, 40(3): 1041-1083.

White, J. P., AND T. Flannery

n.d. Murids from Fais Island. MS in possession of the author.

\section{ABSTRACT}

The third season of archaeological research was carried out on Fais Island in the Caroline Islands at the end of 2005. A deep cultural deposit (more than 3.3 meters) was excavated along the southern coastal deposit from which a number of potsherds, shell artifacts, bone artifacts, and various kinds of natural remains were found. The constant recovery of artifactual remains supports the previous supposition that the island was continuously inhabited since the time of the first colonization. Pigs and dogs (and possibly chickens) have definitely existed on the island since about A.D. 400 afterward. Two charcoal samples obtained from the earliest cultural deposit were securely dated as A.D. 230-410 (Beta-21306) and A.D. 240-420 (Beta213061). These are the earliest dates obtained for the coral islands in the central Caroline Islands. The continuous appearance of potsherds and natural food remains throughout the culture sequence indicates that Fais was permanently settled for the last 1700 years and was not just occupied for a short period of time. On the basis of introduced pottery and domesticated animals, maintaining cultural contacts with high islands could have been a significant way to survive on such small coral islands with limited resources. 